\title{
Prevalence of Distal Symmetric Diabetic Neuropathy among Type 2 Diabetic Patients in Suez Canal University Hospital Outpatient Clinics in Ismailia
}

\author{
Eman A. Ezz Eldeen ${ }^{*}$ Nahed A. Eldahshan, Khaled S. Heissam, \\ Enas H. Mohamed
}

Department of Family Medicine, Faculty of Medicine, Suez Canal University, Egypt

\begin{abstract}
Background: The World Health Organization describes diabetes mellitus as the most common endocrine disease in the world. Diabetes mellitus is the most common cause of neuropathy worldwide. About $25-50 \%$ of diabetic patients in developed countries have peripheral polyneuropathy. Prolonged B12 deficiency can lead to nerve degeneration and irreversible neurological damage. Aim: This study was conducted aiming at assessing the prevalence of peripheral neuropathy among type 2 diabetic patients attending Suez Canal University Outpatient clinics. A secondary objective of the study was to identify the relation between vitamin $B$ and diabetic neuropathy. Patients and Methods: A convenience sample was used in this cross sectional study, which was conducted in Suez Canal University Outpatient clinics. A total of 362 type 2 diabetic patients, responded to questionnaire and screening examination, using the Michigan Neuropathy Screening Instrument (MNSI). Results: The present study showed that the mean age was $55.12 \pm 9.26$ and about $81.2 \%$ of the study population were females. More than, two-thirds (69.1\%) were married. In addition, about $37 \%$, had diabetes for over 10 years. The study revealed that $34 \%$ of the study population had peripheral neuropathy according to Michigan score results. The most frequent symptom was numbness (83.4\%). Vibration perception was absent in half of patients. Nearly monofilament was absent in one-third (34.5\%) of patients. As regards vitamin B12 supplements, the results revealed that about $\mathbf{8 7 . 1 \%}$ of neuropathic patients had taken vitamin B12. Conclusion: The result of the present study concluded that peripheral neuropathy is a very common problem in diabetic patients, which accounts $34 \%$ in our study.
\end{abstract}

Keywords: Diabetic neuropathy;MNSI;vitamin B treatment

\section{Introduction}

Type 2 diabetes has reached epidemic levels in most populations and epidemiological evidence suggests that unless effective preventive measures are implemented, the prevalence continue to raise globally ${ }^{(1)}$. Egypt also is in the world's top 10 in terms of the highest number of people with diabetes ( 3.9 million) in 2003 and this number is expected to increase to 7.8 million by $2025^{(2)}$. The high economic burden of diabetes in the Eastern Mediterranean and Middle East region is due to the high prevalence rate coupled with the high cost of diabetes and limited resources. A less affluent country such as Egypt is estimated to spend between 486 and 892 million dollars on diabetes care ${ }^{(2)}$. In a cross-sectional multicenter study in Iran which aimed to

*Corresponding Author: eman.ezz3114@yahoo.com. 
study the overall prevalence of diabetic neuropathy reported that the diabetic neuropathy was 38\% among type 2 diabetes mellitus ${ }^{(3)}$.The early recognition and appropriate management of neuropathy in the patient with diabetes is important ${ }^{(4)}$. In 40 $50 \%$ of people with diabetes mellitus type 1 or type 2 , detectable peripheral neuropathy develops within 10 years of the onset of diabetes, and the neuropathic pain associated with symptomatic disease is frequently bothersome ${ }^{(5-6)}$. Vitamin B12 plays a vital role in the metabolism of fatty acids essential for the maintenance of nerve myelin. Prolonged $B_{12}$ deficiency can lead to nerve degeneration and irreversible neurological damage $^{(7)}$. The treatment of diabetic neuropathy can be a frustrating experience for both physicians and patients, and the clinical effectiveness of vitamin B12 therapy on diabetic peripheral neuropathy is still unclear. Role of family physician in early detection of peripheral diabetic neuropathy that he should educate all patients with diabetes about proper foot care \&check their feet daily (grade C) ${ }^{(8)}$.

\section{Subjects and Methods}

The current study is a cross sectional descriptive one. It was carried out at Suez Canal University Hospital outpatient clinic in Ismailia. A Semi-structured questionnaire was developed by the researcher revised by the supervisors and validated according to pilot study on 10 diabetic patient. The questionnaire is composed of four parts: Part one: contained some selected demographic variables as age, gender, residence, marital status, family size, address, occupation, Income sufficiency, educational background. Part two: questions about disease: duration of DM ( $<5$ years, 5-10 years, $>10$ years), presence of diabetic complication. Part three: including complete drug history including; Antidiabetic drugs (duration, form, frequency, regularity, dose). Antiplatelet drugs (duration, form, frequency, regularity, and dose). Supplements vitamin B6 and B12 (tablets, injections), Duration of usage (<1 month, 1-3 months, 3-6 months, $>6$ months), and frequency (regular or irregular). Part four: Michigan Neuropathy Screening Instrument (MNSI) questionnaire with cut off of $\geq 7$ points (specificity 91\%) and 10-g monofilament test. The $10 \mathrm{~g}$ monofilament is an objective, simple instrument used in screening the diabetic foot for loss of protective sensation. The monofilaments produce a characteristic force perpendicular to the contacting surface. The force of downward contact increases linearly until the monofilament buckles. The ten-point monofilament test was applied on 10 different points on the sole and dorsum of the foot; the absence of sensation in one or more of these points was considered as peripheral neuropathy ${ }^{(9)}$.

\section{Statistical analysis}

Gathered data were processed using SPSS version 15 (SPSS Inc., Chicago, IL, USA). Quantitative data were expressed as means \pm SD while qualitative data were expressed as numbers and percentages (\%). Student $t$ test was used to test significance of difference for quantitative variables and Chi Square was used to test significance of difference for qualitative variables. To measure the effect size and the strength of association with cardiovascular risk factor among diabetic patients with and without DSN, odds ratios (OR) were calculate with $95 \% \mathrm{Cl}$. A probability value of $\mathrm{p}$-value $<0.05$ was considered statistically significant.

\section{Results}

This study was carried on 362 type 2 diabetic patients attending Suez Canal University Hospital Outpatient Clinic in Ismailia. It was 
obvious that of all subjects, more than $3 / 4^{\text {th }}$ (81.2\%) were females, the mean age was 55.12 \pm 9.26 . According to the residence, about half (51.1\%) of the patients were resident in urban areas. About $53.3 \%$ were illit- erate, $35.2 \%$ of the patients could read and write. More than (2/3) $69.1 \%$ were married, 69.9 were not working. Regarding income the majority of them (80.4\%) had sufficient income as shown in Table 1

Table 1: Socio demographic characteristics of study population $(\mathrm{N}=362)$

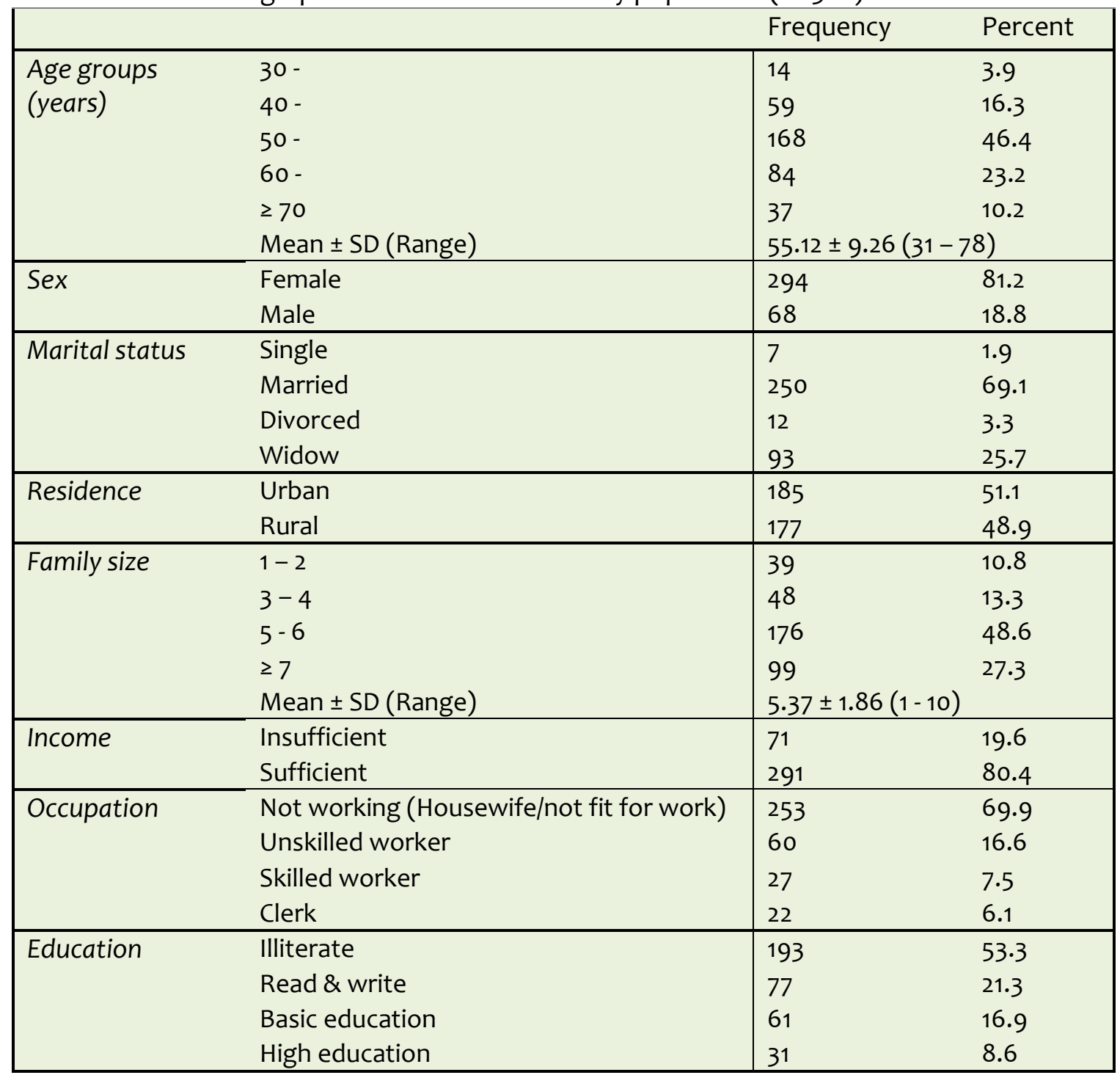

The prevalence of diabetic neuropathy patients according to Michigan score is shown in Figure (1). The range of Michigan score was $0-13$ (mean $=5.53 \pm 2.3$ ). while more than one third (34\%) of studied population had peripheral neuropathy according to Michigan score Figure (2).By Illustrating the prevalence of neuropathy according to different screening tools. it was $34 \%$ (by using questionnaire), $45.3 \%$ (by using vibra tion perception), while it was $26.8 \%$ (by monofilament) table (2). It was found that prevalence of neuropathy by using vibration sensation and monofilament was $23.5 \%$ while by questionnaire and vibration Sensation was $20.4 \%$. Table (3) shows the diagnostic performance of different instruments used. The best tools were vibration sensation and monofilament together which had high sensitivity (87.6\%) and 


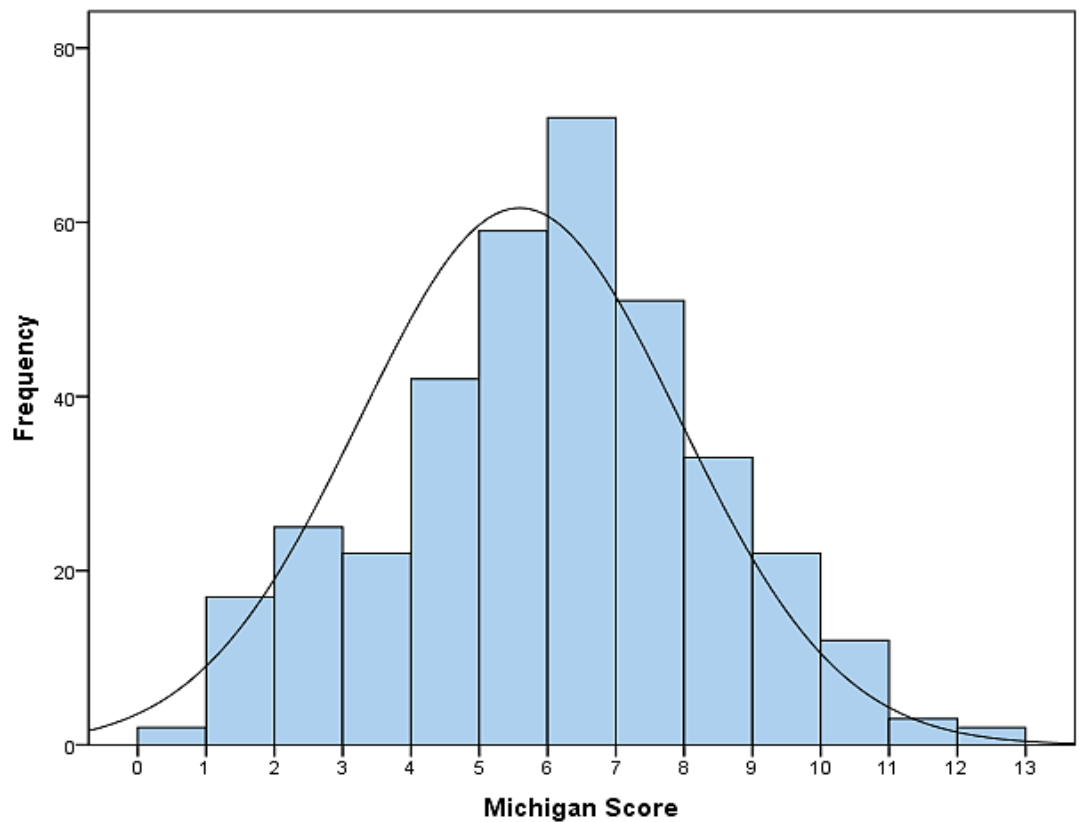

Figure 1: Distribution of diabetic patients according to Michigan score (range 0-13) (mean= $5.53 \pm 2.3$ ).

high specificity (100\%). The least sensitive (47.4\%) and least specific (70.9\%) instrument was questionnaire. To explain the relation between neuropathy \& sociodemographic characteristic it was found that half $(50.6 \%)$ of neuropathic patients were $50-60$ years old. There was statistical- ly highly significant relationship between age and diabetic neuropathy $(P<0.05)$. About gender, the majority of patients were females and this represents (81.2\%). There was no statistically significant relationship between gender and diabetic neuropathy ( $p>0.05$, Table 4$)$.

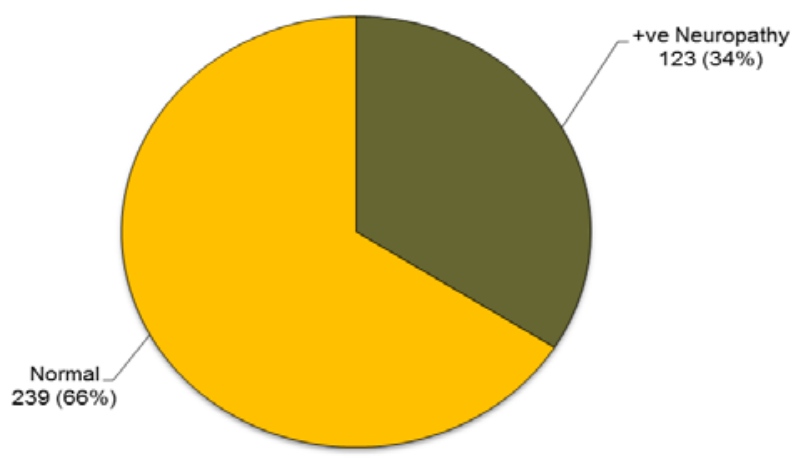

Figure 2: Frequency of peripheral neuropathy in the studied population

(according to Michigan questionnaire score)

While studying the relation between neuropathy and disease characteristics. Regards the relation between neuropathy and duration of diabetes mellitus in the studied population, more than half (61.2\%) of patients who had neuropathy had diabe- 
tes $>10$ years. There was statistically highly significant relationship between duration of DM and neuropathy $(p<0.05)$. About 3/4th (74.1\%) of neuropathic patients had complication. There was statistically no significant relationship between complication and diabetic neuropathy $(p>0.05$, table 5). the relation between neuropathy and medications characteristics. Regarding antidiabetic drugs, neuropathic patients

Table 2: The prevalence of neuropathy according to different screening instruments $(\mathrm{N}=362)$

\begin{tabular}{|l|cc|}
\hline Instruments & Frequency & $\%$ \\
\hline Questionnaire & 123 & $34.0 \%$ \\
Vibration perception & 164 & $45.3 \%$ \\
Monofilament & 97 & $26.8 \%$ \\
Vibration Sens. + Monofilament & 85 & $23.5 \%$ \\
Questionnaire +Vibration Sens. & 74 & $20.4 \%$ \\
Questionnaire + Monofilament & 46 & $12.5 \%$ \\
Questionnaire +Vibration Sens. + Monofilament & 85 & $23.5 \%$ \\
\hline
\end{tabular}

taking oral hypoglycemic drugs were nearly equal neuropathic patients taking insulin. There was statistically highly significant relationship between neuropathy antidiabetic drugs $(p<0.05)$. The relation between neuropathy and vitamin B12 reveals that more than $3 / 4$ th $(87.1 \%)$ of neuropathic patients had taken vitamin B12 and more than $2 / 3$ rd (64.9\%) of neuropathic patients had taken vitamin B12 regularly. There was statistically highly significant relationship between neuropathy and vitamin B12 drugs $(p<0.05)$ as illustrated in table (6). While the predictors for diabetic neuropathy as age, marital status, family size, duration of diabetes and regularity for taking vitamin $B$ was significant as showed in table (7).

\section{Discussion}

The study aimed to improve the quality of care for diabetic patients. The study had assessed the prevalence of diabetic distal symmetric neuropathy among 362 patients with type II diabetes attending Suez Canal university outpatient clinic in Ismailia city, Egypt. In the present study, the the prevalence of peripheral neuropathy was 34\%

Table 3: Diagnostic performance of different instruments for screening of neuropathy $(\mathrm{N}=362)$

\begin{tabular}{|l|llll|}
\hline & $\begin{array}{l}\text { Sensitivity\% } \\
(95 \% \mathrm{Cl})\end{array}$ & $\begin{array}{l}\text { Specificity\% } \\
(95 \% \mathrm{Cl})\end{array}$ & $\begin{array}{l}\text { PPV\% } \\
(95 \% \mathrm{Cl})\end{array}$ & $\begin{array}{l}\text { NPV\% } \\
(95 \% \mathrm{Cl})\end{array}$ \\
\hline Questionnaire & 47.4 & 70.9 & 37.4 & 78.7 \\
& $(37.2-57.8)$ & $(65.1-76.3)$ & $(28.8-46.6)$ & $(72.9-83.7)$ \\
\hline Vibration Sens. & 87.6 & 70.2 & 51.8 & 93.9 \\
& $(79.4-93.4)$ & $(64.3-75.6)$ & $(43.9-59.7)$ & $(89.6-96.8)$ \\
\hline Vibration Sens. + & 87.6 & 100 & 100 & 95.7 \\
Monofilament & $(79.4-93.4)$ & $(98.6-100)$ & $(95.7-100)$ & $(92.5-97.7)$ \\
\hline Questionnaire + & 42.3 & 87.5 & 55.4 & 80.6 \\
Vibration Sens. & $(32.3-52.7)$ & $(83.0-91.3)$ & $(43.4-67.0)$ & $(75.5-85.0)$ \\
\hline Questionnaire + & 47.4 & 100 & 100 & 83.9 \\
Monofilament & $(37.2-57.8)$ & $(98.6-100)$ & $(92.3-100)$ & $(79.3-87.7)$ \\
\hline
\end{tabular}

Monofilament is gold standard test 
Table 4: Relation between neuropathy and sociodemographic characteristics ( $N=362)$

\begin{tabular}{|c|c|c|c|c|c|c|}
\hline & \multicolumn{2}{|c|}{$\begin{array}{l}\text {-ve neuropathy } \\
\qquad(n=277)\end{array}$} & \multicolumn{2}{|c|}{$\begin{array}{l}\text { + ve neuropathy } \\
\qquad(n=85)\end{array}$} & \multirow{2}{*}{$p$-value } \\
\hline & & No. & $\%$ & No. & $\%$ & \\
\hline \multirow{5}{*}{$\begin{array}{l}\text { Age groups } \\
\text { (years) }\end{array}$} & $30-$ & 14 & 5.1 & 0 & 0 & \multirow[t]{5}{*}{$<0.001^{*}$} \\
\hline & $40-$ & 54 & 19.5 & 5 & 5.9 & \\
\hline & $50-$ & 125 & 45.1 & 43 & 50.6 & \\
\hline & $60-$ & 65 & 23.5 & 19 & 22.4 & \\
\hline & $\geq 70$ & 19 & 6.9 & 18 & 21.2 & \\
\hline \multirow[t]{2}{*}{ Sex } & Female & 225 & 81.2 & 69 & 81.2 & \multirow[t]{2}{*}{0.992} \\
\hline & Male & 52 & 18.8 & 16 & 18.8 & \\
\hline \multirow[t]{4}{*}{ Marital status } & Single & 5 & 1.8 & 2 & 2.4 & \multirow{4}{*}{$\begin{array}{l}\text { 0.01* } \\
\text { Fisher }\end{array}$} \\
\hline & Married & 203 & 73.3 & 47 & $55 \cdot 3$ & \\
\hline & Divorced & 7 & 2.5 & 5 & 5.9 & \\
\hline & Widow & 62 & 22.4 & 31 & 36.5 & \\
\hline \multirow[t]{2}{*}{ Residence } & Urban & 135 & 48.7 & 50 & 58.8 & \multirow[t]{2}{*}{0.104} \\
\hline & Rural & 142 & 51.3 & 35 & 41.2 & \\
\hline \multirow[t]{4}{*}{ Family size } & $1-2$ & 36 & 13.0 & 3 & 3.5 & \multirow[t]{4}{*}{$0.045^{*}$} \\
\hline & $3-4$ & 32 & 11.6 & 16 & 18.8 & \\
\hline & $5-6$ & 134 & 48.4 & 42 & 49.4 & \\
\hline & $\geq 7$ & 75 & 27.1 & 24 & 28.2 & \\
\hline \multirow[t]{2}{*}{ Income } & Insufficient & 43 & 15.7 & 25 & 29.4 & \multirow[t]{2}{*}{$0.005^{*}$} \\
\hline & Sufficient & 231 & 84.3 & 60 & 70.6 & \\
\hline \multirow[t]{4}{*}{ Occupation } & Not working & 148 & 53.4 & 45 & 52.9 & \multirow[t]{4}{*}{0.279} \\
\hline & Unskilled worker & 54 & 19.5 & 23 & 27.1 & \\
\hline & Skilled worker & 48 & 17.3 & 13 & $15 \cdot 3$ & \\
\hline & Clerk & 27 & 9.7 & 4 & 4.7 & \\
\hline \multirow[t]{4}{*}{ Education } & Illiterate & 148 & 53.5 & 45 & 52.9 & \multirow[t]{4}{*}{0.279} \\
\hline & Read \& write & 54 & 19.5 & 23 & 27.1 & \\
\hline & Basic education & 48 & 17.3 & 13 & $15 \cdot 3$ & \\
\hline & High education & 27 & 9.7 & 4 & 4.7 & \\
\hline
\end{tabular}

N.B. Neuropathy diagnosis based on combined vibration \& monofilament results

according to Michigan score while the prevalence reported increased to $45.3 \%$ when evaluated by vibration perception and decreased to $26.8 \%$ when evaluated by monofilament test. In accordance to our study, an Iranian study had assessed the prevalence of peripheral neuropathy in diabetic patients using different evaluation methods, they detected diabetic neuropathy in $31.9 \%$ of studied diabetic patients (according to Michigan score), and according to 10-point monofilament test, peripheral diabetic neuropathy was detected in
$31.7 \%$ of patients ${ }^{(3)}$. In a 25 - years study performed on 4400 diabetics (1947-1973), the prevalence rate of neuropathy based on diagnostic criteria such as the absence of Achilles tendon reflex and the abnormal perception sensation was reported as $7.5 \%$ at the baseline, reached up to $50 \%$ in the end of study (after 25 years follow-up) ${ }^{(10)}$. We have found that best sensitivity and specificity for diagnosis of peripheral neuropathy is by combining both vibration perception test and monofilament test (87.6\% sensitivity and $100 \%$ specificity). 
Table 5: Relation between neuropathy and disease characteristics $(\mathrm{N}=362)$

\begin{tabular}{|c|c|c|c|c|c|c|}
\hline & \multicolumn{2}{|c|}{$\begin{array}{l}\text { - ve neuropathy } \\
\quad(n=277)\end{array}$} & \multicolumn{2}{|c|}{$\begin{array}{l}\text { +ve neuropathy } \\
(n=85)\end{array}$} & \multirow[t]{2}{*}{$p$-value } \\
\hline & & No. & $\%$ & No. & $\%$ & \\
\hline \multirow{3}{*}{$\begin{array}{l}\text { Duration of } \\
\text { DM (yrs) }\end{array}$} & $<5$ & 99 & 35.7 & 16 & 18.8 & \multirow[t]{3}{*}{$<0.001^{*}$} \\
\hline & $5-10$ & 96 & 34.7 & 17 & 20.0 & \\
\hline & $>10$ & 82 & 29.6 & 52 & 61.2 & \\
\hline \multirow[t]{2}{*}{ Complications } & No & 75 & 27.1 & 22 & 25.9 & \multirow[t]{2}{*}{0.828} \\
\hline & Yes & 202 & 72.9 & 63 & 74.1 & \\
\hline \multirow{2}{*}{$\begin{array}{l}\text { Co-morbid } \\
\text { conditions }\end{array}$} & No & 126 & 45.5 & 33 & 38.8 & \multirow[t]{2}{*}{0.279} \\
\hline & Yes & 151 & 54.5 & 52 & 61.2 & \\
\hline
\end{tabular}

N.B. Neuropathy diagnosis based on combined vibration \& monofilament results

$\mathrm{CHD}=$ Coronary Heart Diseases; $C K D=$ Chronic Kidney Diseases

The prevalence of peripheral neuropathy was estimated to be $23.5 \%$ using these two tests. Similar to the present study, certain previous studies $^{(11-13)}$ have considered the combination of vibration perception test and the 10-point monofilament test as an accurate diagnostic tool in the early diagnosis of DPN. The present study has evaluated the influence of multiple demographic and social factors on incidence of peripheral neuropathy. We have found that older age, larger family size, irregular vitamin B intake and longer duration of disease are significant independent risk factors for peripheral diabetic neuropathy. Similarly, Tabatabaei-Malazy and colleagues ${ }^{(3)}$ have also studied the influence of some demographic factors on prevalence of diabetic

Table 6: Relation between neuropathy and medications characteristics $(\mathrm{N}=362)$

\begin{tabular}{|c|c|c|c|c|c|c|}
\hline & & \multicolumn{2}{|c|}{$\begin{array}{l}\text {-ve neuropathy } \\
\qquad(n=277)\end{array}$} & \multicolumn{2}{|c|}{$\begin{array}{l}\text { +ve neuropathy } \\
(n=85)\end{array}$} & \multirow[t]{2}{*}{$\begin{array}{c}p- \\
\text { value }\end{array}$} \\
\hline & & No. & $\%$ & No. & $\%$ & \\
\hline \multirow[t]{3}{*}{ Anti-Diabetic drugs } & Oral & 154 & 55.6 & 35 & 41.2 & \multirow{3}{*}{$\begin{array}{c}0.039 \\
*\end{array}$} \\
\hline & Insulin & 80 & 28.9 & 36 & 42.4 & \\
\hline & Mixed & 39 & 14.1 & 14 & 16.5 & \\
\hline \multirow{2}{*}{$\begin{array}{l}\text { Regularity of Anti- } \\
\text { Diabetic drugs }\end{array}$} & Irregular & 4 & 1.4 & 0 & 0 & \multirow{2}{*}{$\begin{array}{l}0.576 \\
\text { Fisher }\end{array}$} \\
\hline & Regular & 269 & 97.1 & 85 & 100.0 & \\
\hline \multirow[t]{2}{*}{ Anti-Platelet drugs } & No & 200 & 72.5 & 50 & 58.8 & \multirow[t]{2}{*}{$0.017^{*}$} \\
\hline & Yes & 76 & 27.5 & 35 & 41.2 & \\
\hline \multirow{2}{*}{$\begin{array}{l}\text { Regularity of Anti-Platelet } \\
\text { drugs }\end{array}$} & Irregular & 18 & 23.7 & 3 & 8.6 & \multirow[t]{2}{*}{0.063} \\
\hline & Regular & 58 & 76.3 & 32 & 91.4 & \\
\hline \multirow[t]{2}{*}{ Vitamin B12 } & No & 71 & 25.6 & 11 & 12.9 & \multirow[t]{2}{*}{$0.014^{*}$} \\
\hline & Yes & 206 & 74.4 & 74 & 87.1 & \\
\hline \multirow[t]{2}{*}{ Regularity of Vitamin B12 } & Irregular & 110 & 53.4 & 26 & 35.1 & \multirow[t]{2}{*}{$0.01 *$} \\
\hline & Regular & 96 & 46.6 & 48 & 64.9 & \\
\hline
\end{tabular}

N.B. Neuropathy diagnosis based on combined vibration \& monofilament results

neuropathy as evaluated by different measurement tools. They have reported that male sex is associated with lower risk of neuropathy. However, age over 50, diabetes duration over 10 years were signifi- cant risk factors associated with increased risk of peripheral diabetic neuropathy ${ }^{(3)}$. Different studies evaluating the effect of various factors on diabetic neuropathy have reported controversial results. In a 
case-control study conducted on some 110 diabetic patients in Dr. Shariati Hospital, Bouya et al. ${ }^{(14)}$ assessed the prevalence of peripheral neuropathy and the factors influencing this rate using MNSI and the electro diagnostic methods (NCV, EMG).

Table 7: Multiple logistic regression analysis for the predictors of neuropathy $(\mathrm{N}=362)$

\begin{tabular}{|l|cccc|}
\hline & Coefficient & $p$-value & $\begin{array}{c}\text { Adjusted } \\
\text { Odds Ratio }\end{array}$ & $\begin{array}{c}95 \% \text { Confidence } \\
\text { Interval }\end{array}$ \\
\hline - Age & 0.048 & $0.010^{*}$ & 1.049 & $1.011-1.089$ \\
- Marital status & 1.022 & $0.009^{*}$ & 2.780 & $1.289-5.993$ \\
- Family size & 0.333 & $0.001^{*}$ & 1.395 & $1.138-1.710$ \\
- Income & 0.724 & 0.070 & 2.062 & $0.942-4.515$ \\
- Duration of disease & 0.630 & $0.008^{*}$ & 1.878 & $1.177-2.996$ \\
- Insulin & 0.467 & 0.232 & 1.595 & $0.742-3.429$ \\
- Mixed (oral + insulin) & 0.130 & 0.786 & 1.139 & $0.445-2.916$ \\
- Antiplatelet drugs & -0.044 & 0.895 & 0.957 & $0.498-1.840$ \\
- Regularity of vitamin B & 1.014 & $0.002^{*}$ & 2.757 & $1.450-5.240$ \\
- Impaired circulation & 0.403 & 0.237 & 1.497 & $0.767-2.922$ \\
- General asthenia & 1.042 & $0.010^{*}$ & 2.834 & $1.287-6.242$ \\
- Constant & -7.574 & $<0.001^{*}$ & 0.001 & \\
\hline
\end{tabular}

Reference categories: Marital status (married) Income (sufficient), form of anti-diabetic drugs (oral), anti-platelets (No), regularity of vit B (regular) impaired circulation (No), general asthenia (No).

Model fit, $\left(\chi^{2}=65.8 ; p<0.001^{*}\right)$, * Statistically significant at $p<0.05$

In this study, there was no statistically significant relation between smoking, the use of Angiotensin-Converting Enzyme inhibitors' drugs (ACEl drugs), hypertension, high cholesterol levels, diabetes treatment regimen and the prevalence of neuropathy; the influence of age, quality of diabetes control and duration of the disease on the development of neuropathy, however, was significant. The risk of developing neuropathy in men was 2.9 times higher than women. Poor controlled diabetes and every year increase in the duration of diabetes increased the risk of developing neuropathy by 0.3 and 1.1 times, respectively ${ }^{(15)}$. Similarly, Boru et al. ${ }^{(16)}$ have found that age, the duration of diabetes, and poor controlled diabetes were the main risk factors contributing to the condition. In the Nigeria study ${ }^{(17)}$, however, the duration of diabetes, age, the status of diabetes control, high blood pressure, retinopathy, and $\mathrm{HbA1c}$ level were the main factors increasing the risk of diabetic neuropathy by 1.34 times $(r=0.295)$. We conducted this crosssectional study to explore the relation between vitamin $B$ and diabetic peripheral neuropathy. It was conducted on 362 patients. More than $3 / 4$ th $(77.3 \%)$ of them had taken vitamin B. More than half $(57.9 \%)$ of them had been taken the vitamins in the injection form. About half (51.4\%) of the patients had taken the vitamins regularly and about $2 / 3$ rd $(70.0 \%)$ of them had taken the vitamins $>6$ months. Our results revealed that about $(87.1 \%)$ of neuropathic patients had taken vitamin B. Abbas (1997) was the largest study, accounting for 200 of the 488(41\%) participants treated with vitamin B. ${ }^{(18)}$ the age range of the participants was from 18 to 74 years. Eleven studies were on diabetic neuropathy and two on alcoholic neuropathy ${ }^{(20-21)}$. None of the studies had documented vitamin B deficiency. one excluded participants with vitamin B12 deficiency ${ }^{(21)}$. The main results of this review showed in the comparison of vitamin $B$ with placebo, two small trials showed no 
significant short-term ( 3 months) benefit in pain intensity while one of trials showed a small significant benefit in vibration detection from oral benfotiamine, derivatives of thiamine. In the larges of two trials comparing different doses of vitamin B complex, there was some evidence that higher doses resulted in a significant short-term reduction in pain and improvement in parathesiae, in composite outcome combining pain, temperature and vibration and in a composite outcome combining pain, numbness and parathesiae.

\section{Conclusion}

In conclusion, peripheral diabetic neuropathy is a very common and serious problem among diabetic patients. A combination of both vibration perception test and 10-point filament test showed best sensitivity and specificity in detection of peripheral neuropathy. Other factors such as; older age and longer duration of diabetes must be taken in consideration.

\section{Acknowledgments}

The authors would like to thank all participants in the study.

\section{References}

1. Alberti KG, Zimmet $P$, Shaw J. International Diabetes Federation: a consensus on Type 2 diabetes prevention. Diabet Med 2007: 24(5):451-463.

2. Harati H, Hadaegh F, Saadat N, Azizi F. Population-based incidence of Type 2 diabetes and its associated risk factors: results from a six-year cohort study in Iran. BMC Public Health 2009:9:186.

3. Sicree R, Shaw JE, Zimmet PZ. The global burden of diabetes. In: Gan D, editor. Diabetes Atlas. 2nd ed. Brussels, Belgium: International Diabetes Federation; 2003. 15-71.

4. Boulton AJ, Vinik AL, Arezzo JC, Bril. V, Feldman EL, Freeman R, Malik RA, Maser
RE, Sosenko JM, Ziegler D. American Diabetes Association Diabetic neuropathies: a statement by the American Diabetes Association. Diabetes Care 2005; 28:956-962

5. Partanen J, Niskanen L, Lehtinen J, Mervaala E, Siitonen O, Uusitupa M. Natural history of peripheral neuropathy in patients with non-insulin-dependent diabetes mellitus. N Engl J Med 1995:333 (2):89-94.

6. Anonymons. The effect of intensive treatment of diabetes on the development \& progression of long term complications in insulin dependent diabetes mellitus. The Diabetes Control an Complication Trial Research Group. N Engl J Med 1993: 329-977-86.

7. Scalabrino G, Buccellato FR, Veber D, Mutti E. New basis of the neurotrophic action of vitamin B12. Clin Chem lab Med. 2003:41(11):1435-1437.

8. Armstrong DG, Lavery LA. Diabetic foot ulcers: prevention, diagnosis and classification. Am Fam Physician. 1998: 57(6):1325-1332.

9. Feldman EL, Stevens MJ, Thomas PK, Brown MB, Canal N, Greene DA. A practical two-step quantitative clinical and electrophysiological assessment for the diagnosis and staging of diabetic neuropathy. Diabetes Care 1994:17 (11): 12811289.

10. Pirart J. Diabetes mellitus and its degenerative complications: a prospective study of 4400 patients observed between 1947 and 1973. Diabetes Care 1978:1: 168-188, 253-263.

11. Young MJ, Breddy JL, Veves A, Boulton AJ. The prediction of diabetic neuropathic foot ulceration using vibration perception thresholds. A prospective study-Diabetes Care 1994: 17(6):557-560.

12. Kumar S, Fernando DJ, Veves A, Knowles EA, Young MJ, Boulton AJ. SemmesWeinstein monofilaments: a simple, effective and inexpensive screening device for identifying diabetic patients at risk of foot ulceration. Diabetes Res Clin Pract. 1991: 13(1-2):63-67. 
13. Olmos PR, Cataland S, O'Dorisio TM, Casey CA, Smead WL, Simon SR. The Semmes- Weinstein monofilament as a potential predictor of foot ulceration in patients with noninsulin- dependent diabetes. Am J Med Sci. 1995; 309(2): 76-82.

14. Dutch Association of Neurology (NVN), Dutch Association of Clinical Neurophysiology (NVKNF): Guideline Polyneuropathy of the Dutch Institute for Healthcare Improvement (CBO). Alphen a/d Rijn, the Netherlands: van Zuiden,2005.

15. Bouya F, Bandarian F, Larijani B, Pajouhi $M$, Nooraei $M$, Lotfi J. Potential risk factors for diabetic neuropathy: a casecontrol study. BMC Neurol. 2005; 5, 24.

16. Boru UT, Alp R, Sargin H, Koçer A, Sargin $M$, Lüleci $A$, Yayla A. Prevalence of peripheral neuropathy in type 2 diabetic patients attending a diabetes center in Turkey. Endocr J. 2004;51(6):563-567.

17. Ugoya SO, Ugoya TA, Puepet FH.Risk determinants of diabetic peripheral neuropathy in Jos, North. Central Nigeria. J of Chinese Clinical Medicine 2008; 3(5): 285-291.

18. Abbas ZG, Swai AB.Evaluation of the efficacy of thiamine and pyridoxine in the treatment of symptomatic diabetic peripheral neuropathy. East Afr Med J 1997;74(12):803-808.

19. Woelk H, Lehrl S, Bitsch R, Köpcke W. Benfotiamine in treatment of alcoholic polyneuropathy: an 8-week randomized controlled study (BAPI study).Alcohol alcohol 1998;33(6):631-638.

20. Kovrazhkina EA, Aĭriian Nlu, Serkin GV, Glushkov KS, Pavlov NA, Gekht AB, Stakhovskaia LV, Skvortsova VI. Possibilities and perspective of birlition usage in the treatment of alcoholic polyneuropathy. Zh Nevrol Psikhiatr Im S S Korsakova 2004;104(2):33-37.

21. Abbott CA, Malik RA, van Ross ER, Kulkarni J, Boulton AJ. Prevalence and Characteristics of Painful Diabetic Neuropathy in a large Community-Based Diabetic Population in the U.K. Diabetes Care 2011: ;34 (10):2220-2224. 